\title{
Electron-Capture-Induced Dissociation of Protoporphyrin IX Ions
}

\author{
Virgile Bernigaud, ${ }^{a}$ Kasper Drenck, ${ }^{b}$ Bernd A. Huber, ${ }^{a}$ \\ Preben Hvelplund, ${ }^{\mathrm{b}}$ Tristan Jabot, ${ }^{\mathrm{b}}$ Umesh Kadhane, \\ Maj-Britt Suhr Kirketerp, ${ }^{\mathrm{b}}$ Bo Liu, ${ }^{\mathrm{c}}$ Morten Køcks Lykkegaard, ${ }^{\mathrm{b}}$ \\ Bruno Manil, and Steen Brøndsted Nielsen ${ }^{\mathrm{b}}$ \\ ${ }^{a}$ Centre de Recherche sur les Ions, les Matériaux et la Photonique, Caen Cedex 5, France \\ ${ }^{\mathrm{b}}$ Department of Physics and Astronomy, University of Aarhus, Aarhus C, Denmark \\ ${ }^{c}$ Institute of Photo-biophysics, School of Physics and Electronics, Henan University, Kaifeng, China
}

Electron-capture induced dissociation of protoporphyrin cations and anions has been studied. The cations captured two electrons in two successive collisions and were converted to the corresponding even-electron anions. About one fifth of the ions lost a hydrogen atom to become radical anions but otherwise very little fragmentation was observed. The anions captured an electron to become dianions. No hydrogen loss occurred, and the only fragmentation channel observed was loss of $\mathrm{CO}_{2} \mathrm{H}$, to give a doubly charged carbanion. Our results indicate that protoporphyrin ions are very efficient in accommodating one or even two electrons in the lowest unoccupied molecular orbital of the porphyrin macrocycle, and that electron capture induces only limited dissociation. (J Am Soc Mass Spectrom 2008, 19, 809-813) (C) 2008 American Society for Mass Spectrometry

$\mathrm{E}$ lectron-induced fragmentation of biomolecular ions has become a field of surpassing interest after the pioneering work done by McLafferty and Zubarev ten years ago. Most work has focused on peptides and proteins [1-15], oligonucleotides [16], and recently oligosaccharides [17] and lipids [18]. To study the fragmentation channels, three experimental techniques are commonly used in combination with mass spectrometry: (1) electron capture dissociation (ECD), where ions interact with low-energy electrons in an ion trap [1-7]; (2) electron-transfer dissociation (ETD), where the electron donor is an anion [8-12]; and (3) electron-capture induced dissociation (ECID), where ions of high kinetic energy $(\mathrm{keV})$ capture an electron from a gas target-typically sodium or cesium with low ionization energies [13-15]. In contrast to ECD and ETD, ECID works well both for cations and for anions, as has been demonstrated in several papers [13-15, 19, 20], and even singly charged cations can serve as subjects for investigation [21, 22].

To our knowledge there are no reports in the literature on electron capture by isolated porphyrin ions despite the fact that these ions are ubiquitous in nature and play many important roles in biochemistry. In this work, we have therefore studied ECID of protoporphyrin IX (PP) ions (Scheme 1) that can be produced both as

Contribution to the special focus issue "ECD and Related Approaches to Ion Activation," dedicated to Roman Zubarev.

Address reprint requests to Steen Brøndsted Nielsen, University of Aarhus, Department of Physics and Astronomy, Ny Munkegade, DK-8000 Aarhus C, Denmark, e-mail: sbn@phys.au.dk; or to Bo Liu, Institute of Photobiophysics, School of Physics and Electronics, Henan University, Kaifeng, China, e-mail: boliu@henu.edu.cn. positive and negative ions with electrospray ionization (ESI). Coordination of iron to PP gives heme, which is found in the interior of hemoglobin and myoglobin proteins where it acts as a binding center for dioxygen. In our experiments, ions are accelerated to high energies and collided with cesium vapor. The collision interaction time is a few femtoseconds, and it is therefore reasonable to assume a nearly vertical electrontransfer process. Fragmentation is monitored on a timescale of a few microseconds, which is the flight time from the collision cell to the analyzer.

\section{Experimental}

The experimental setup has been described in detail elsewhere [23, 24]. Ions were produced by ESI. Protoporphyrin IX was dissolved in dichloromethane/methanol (1:1) to produce cations and in methanol to produce anions. The ions were accelerated to $50-\mathrm{keV}$ translational energy, and ions with the $m / z$ of interest were selected by a magnet. After collisions with cesium vapor, the product ions were analyzed by an electrostatic analyzer that scanned the kinetic energy of the ions. The spectra are denoted mass-analyzed ion kinetic energy (MIKE) spectra. Experiments were also performed with helium or neon as collision gas to measure collision-induced dissociation (CID) processes.

\section{Computational Details}

Calculations were performed with the GAUSSIAN 98 program package [25]. The $[\mathrm{PP}-\mathrm{H}]^{-}$anion was geometry 


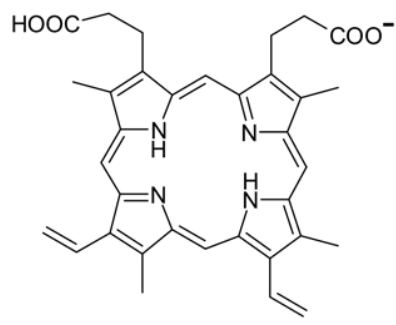

$[\mathrm{PP}-\mathrm{H}]^{-}$

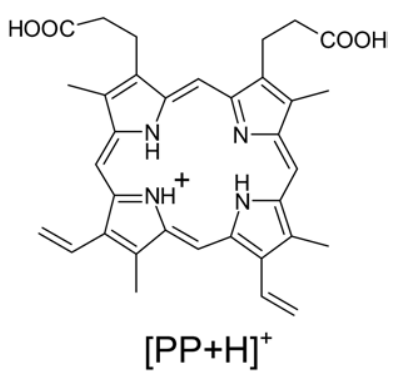

Scheme 1

optimized at the PM3 level, and the lowest unoccupied molecular orbital (LUMO) was calculated at the B3LYP/ $6-31++\mathrm{G}(d)$ level of theory. Energies of the monoanion and the dianion in the same geometry as the monoanion were calculated to determine the vertical electron affinity, and the calculation also provided the singly occupied molecular orbital (SOMO) of the dianion.

\section{Results and Discussion}

First we consider the fragmentation of positive ions. The MIKE spectrum obtained for the collisions between $[\mathrm{PP}+\mathrm{H}]^{+}$cations $(\mathrm{m} / \mathrm{z} 563)$ and helium is shown in Figure $1 \mathrm{~A}$ and resembles previously published fragmentation spectra of similar porphyrin ions [26]. The dominant dissociation channel is loss of $\mathrm{CH}_{2} \mathrm{COOH}$, which is the lowest-energy channel according to work by Charkin et al. [27, 28]. The other peaks are assigned to the loss of one or more side chains: $\mathrm{CH}_{3}(15), \mathrm{CH}_{2} \mathrm{CH}$ (27), $\mathrm{COOH}$ (45), $\mathrm{CH}_{2} \mathrm{COOH}$ (59), $\mathrm{CH}_{2} \mathrm{CH}_{2} \mathrm{COOH}$ (73) (mass). A peak in the center of the spectrum is assigned to the doubly charged $[\mathrm{PP}+\mathrm{H}]^{2+}$ ion formed after electron detachment, likely due to collisions with residual dioxygen in the beam line [29]. The charge-reversal spectrum, ${ }^{+} \mathrm{CR}^{-}$, obtained from collisions with cesium (Figure 1B) reveals that the dominant ion is $[\mathrm{PP}+\mathrm{H}]^{-}$ $(m / z 563)$ formed by capture of two electrons. A narrow scan with higher resolution in the region of the peak shows that the peak has a tail toward lower mass (Figure 2B). We assign this lower mass ion to an ion $(\mathrm{m} / \mathrm{z}$ 562) that has lost one hydrogen atom. A fit of the composite peak to two Gaussians with maxima at 563 and 562 provides an estimate of the ratio of the $m / z-562$ peak to the $m / z-563$ peak of $1 / 5$. To confirm the $\mathrm{H}$ loss channel, we used $\mathrm{CH}_{3} \mathrm{OD}$ instead of $\mathrm{CH}_{3} \mathrm{OH}$ for electrospray to produce deuterated $[\mathrm{PP}+\mathrm{H}]^{+}$ions. The maximum number of exchangeable protons is five $(3 \times$ $\mathrm{NH}+2 \times \mathrm{COOH})$. The $[\mathrm{PP}+\mathrm{H}]^{+}-d_{4}$ ion $(m / z 567)$ was selected by the magnet for collisions with cesium (the beam contained some contamination by the isobaric $\left.\left.{ }^{13} \mathrm{C}-[\mathrm{PP}+\mathrm{H}]\right]^{+}-d_{3}\right)$, and the spectrum of the product anions in the region of the parent mass is shown in Figure 2C. Signal due to D loss is evident at $m / z 565$, and $\mathrm{H}$ loss is also seen. The fragment ions at lower mass (Figure 1B) may be due to electron capture to the parent ion but they may also arise from electron capture to CID fragments, that is, to neutral fragments that are formed together with the positive fragments shown in Figure 1A. The formation of a positive fragment ion that captures two electrons in two consecutive collisions is less likely since it requires a total of three collisions. Still the negatively charged fragments contribute less than $10 \%$ of the total signal from negative ions.

In another experiment, $[\mathrm{PP}-\mathrm{H}]^{-}$anions $(\mathrm{m} / \mathrm{z} 561)$ were collided with helium. The dominant CID channel was loss of $\mathrm{CO}_{2}$ (Figure 3A) but other side-chain losses were also seen, such as loss of $\mathrm{CH}_{3}$ or $\mathrm{CH}_{2}$. This spectrum is to be compared with the ECID spectrum to identify new processes. Thus, when the ions collided with cesium, two new peaks appeared (Figure $3 \mathrm{~B})$ that are tentatively assigned to the $[\mathrm{PP}-\mathrm{H}]^{2-}$ dianion $(m / z$ 280.5) and the dianion that has lost $\mathrm{CO}_{2} \mathrm{H}(\mathrm{m} / \mathrm{z} 258)$. Since the parent ion is nearly symmetric, it is in theory also possible that it would break apart to give a fragment ion with half the $m / z$ of that of the parent ion. The high stability of the macrocycle, however, renders such a process rather unlikely. To exclude it with certainty, we selected the parent ion that contained one ${ }^{13} \mathrm{C}(\mathrm{m} / \mathrm{z} 562)$ and found that the peak moved up with 0.5 to $\mathrm{m} / \mathrm{z}$ of 281 as expected for a dianion (Figure 5). Symmetric breakages should give equal abundance of fragment ions at $m / z 280$ and

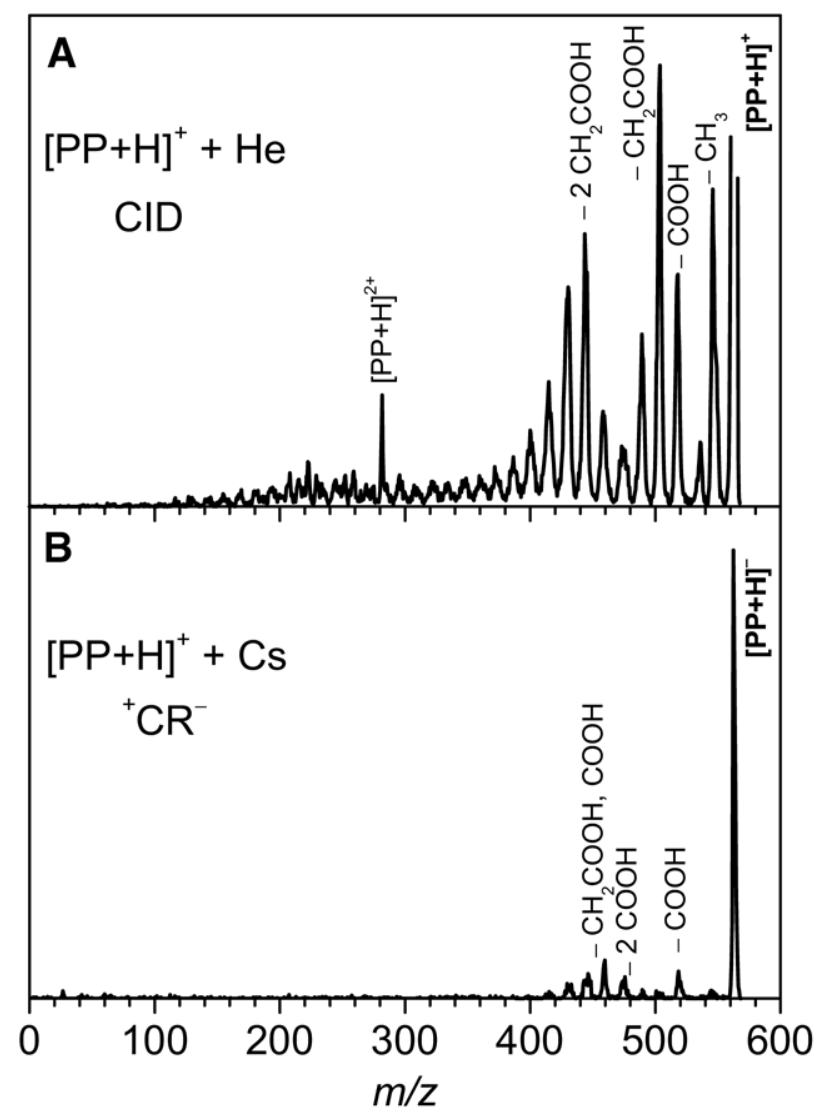

Figure 1. MIKE spectra obtained after collisions between $[\mathrm{PP}+\mathrm{H}]^{+}$and helium (A) and cesium (B). In the former case, positive ions were measured and in the latter negative ions. 
$\mathrm{m} / \mathrm{z} 281$ and can be excluded. According to the calibration, the dianion is intact (Figure 4), but it is hard to conclude with certainty because of the width of the peak (1.5 Thomson). However, it is easy to check whether hydrogens on heteroatoms are lost since these can again be exchanged with deuterium by electrospraying from $\mathrm{CH}_{3} \mathrm{OD}$ instead of $\mathrm{CH}_{3} \mathrm{OH}$.
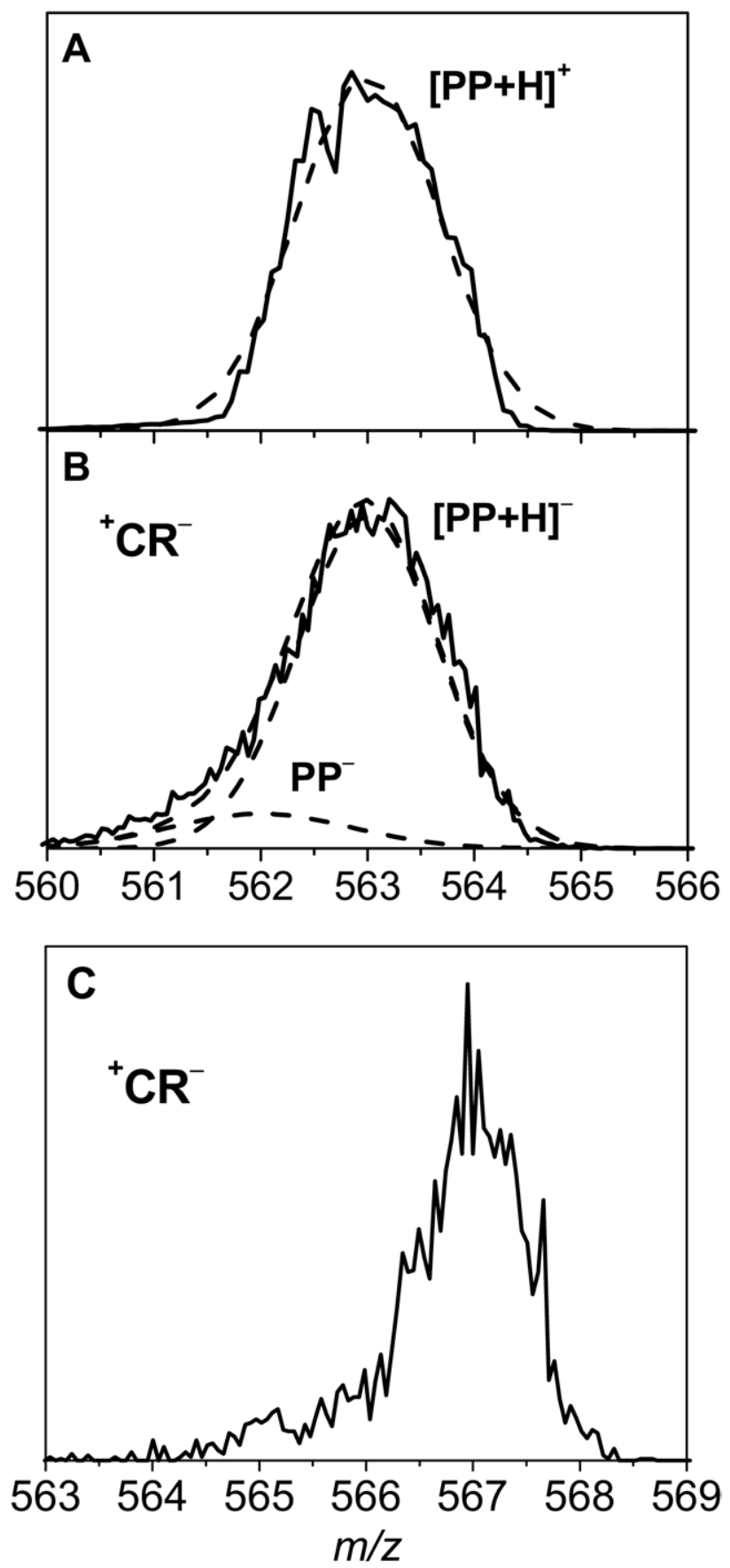

Figure 2. Narrow scans in the region of the parent ion, $[\mathrm{PP}+\mathrm{H}]^{+}$ (A) and the $[\mathrm{PP}+\mathrm{H}]^{-}$ion formed after two collisions with cesium (B). The peaks are described by Gaussians. (C) Narrow scan in the region of the $[\mathrm{PP}+\mathrm{H}]^{-}-d_{4}$ ion formed after two collisions between $[\mathrm{PP}+\mathrm{H}]^{+}-d_{4}$ and cesium. Four of five exchangeable protons are replaced with deuterons in the parent ion.

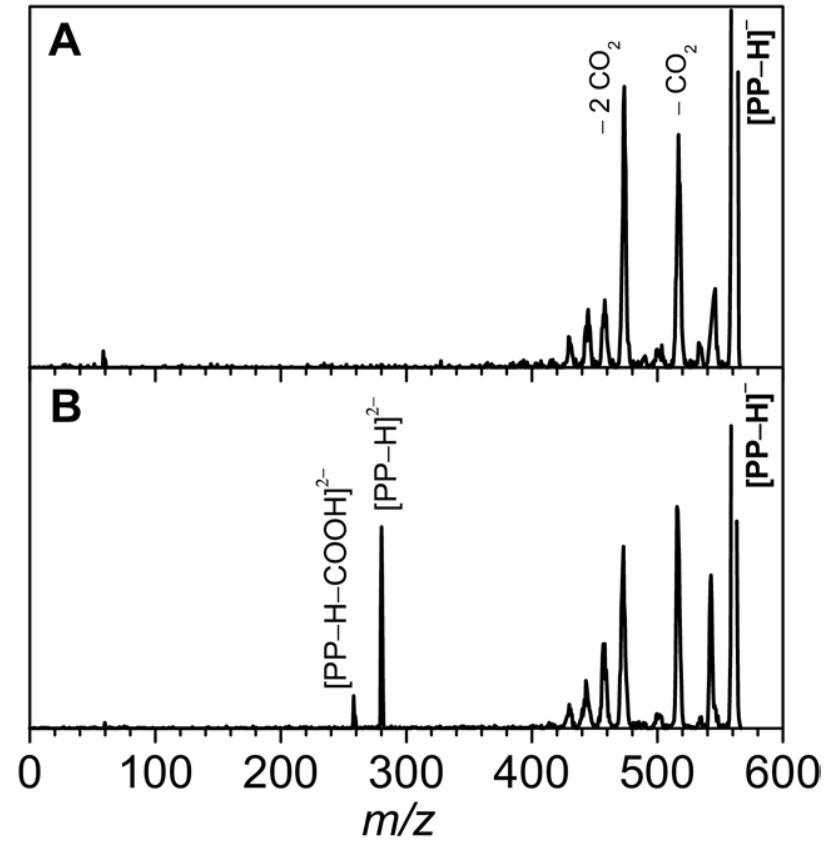

Figure 3. MIKE spectra obtained after collisions between [PP$\mathrm{H}^{-}$and neon (A) and cesium (B). Negative ions are measured.

We therefore selected ions that had exchanged one, two, and three hydrogens with deuteriums (maximum number is three, $2 \times \mathrm{NH}+\mathrm{COOH}$ ) and recorded narrow scans in the region around the dianion (Figure 5). It is evident that the peak does not move, that is, it always appears at half the value of the analyzer voltage to transmit the parent ion, and hence we conclude that hydrogen from a heteroatom is not lost. It is stressed that this is an opposite finding to that of nucleotide anions that after electron capture lost a hydrogen atom from one of the base nitrogens [30]. We do not have the compound deute-

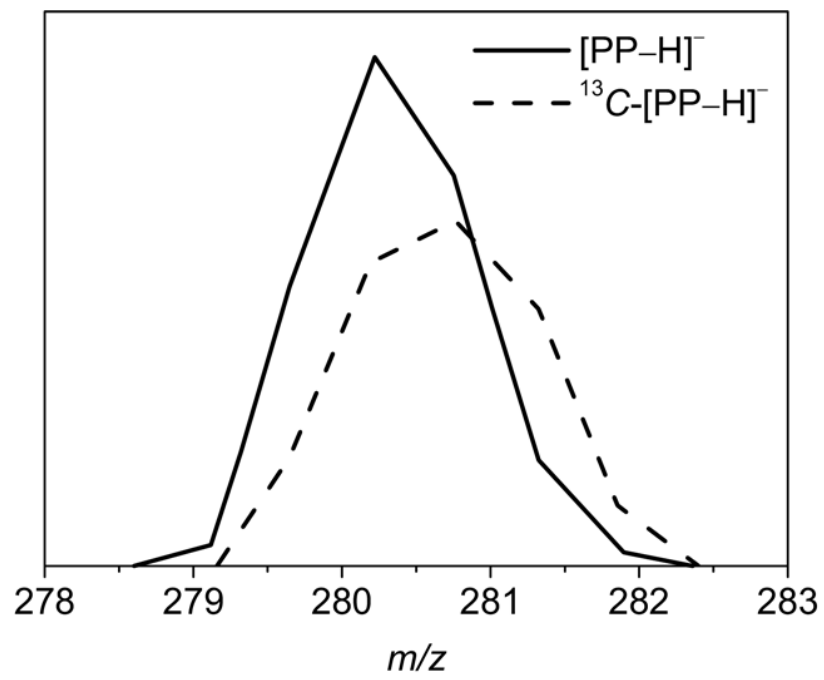

Figure 4. Spectra in the region of the dianion when either $[\mathrm{PP}-\mathrm{H}]^{-}(m / z 561)$ or ${ }^{13} \mathrm{C}-[\mathrm{PP}-\mathrm{H}]^{-}(m / z 562)$ that contains one ${ }^{13} \mathrm{C}$ were selected as parent ions. 
rium labeled at the carbons for a similar experiment and therefore rely on calculations. These indicate that the LUMO (lowest unoccupied molecular orbital) is a $\pi^{*}$ orbital located on the porphyrin macrocycle, but it is not antibonding between carbon and hydrogen (Figure 6); the orbital is similar to the SOMO of the dianion. Finally, we calculated the energies of different $\mathrm{C}-\mathrm{H}$ and $\mathrm{N}-\mathrm{H}$ bonds of the porphyrin and found that it requires more than $3.5 \mathrm{eV}$ to cleave an $\mathrm{N}-\mathrm{H}$ bond and at least $0.8 \mathrm{eV}$ more to cleave a $\mathrm{C}-\mathrm{H}$ bond. Taken together, we find it safe to conclude that no hydrogen loss occurred after electron capture to the $[\mathrm{PP}-\mathrm{H}]^{-}$anion, which is in accordance with the observation of the intact $[\mathrm{PP}+\mathrm{H}]^{-}$anion from double electron capture to the $[\mathrm{PP}+\mathrm{H}]^{+}$cation in the previous experiment. The dianionic fragment likely results from electron capture by the carboxylic acid group instead of the porphyrin ring followed by loss of $\mathrm{COOH}$ to give a carbanion. This competing channel occurs with a probability of about $20 \%$.

We have calculated the electron affinity of the neutral porphyrin macrocycle to be $2.0 \mathrm{eV}$ at the B3LYP/

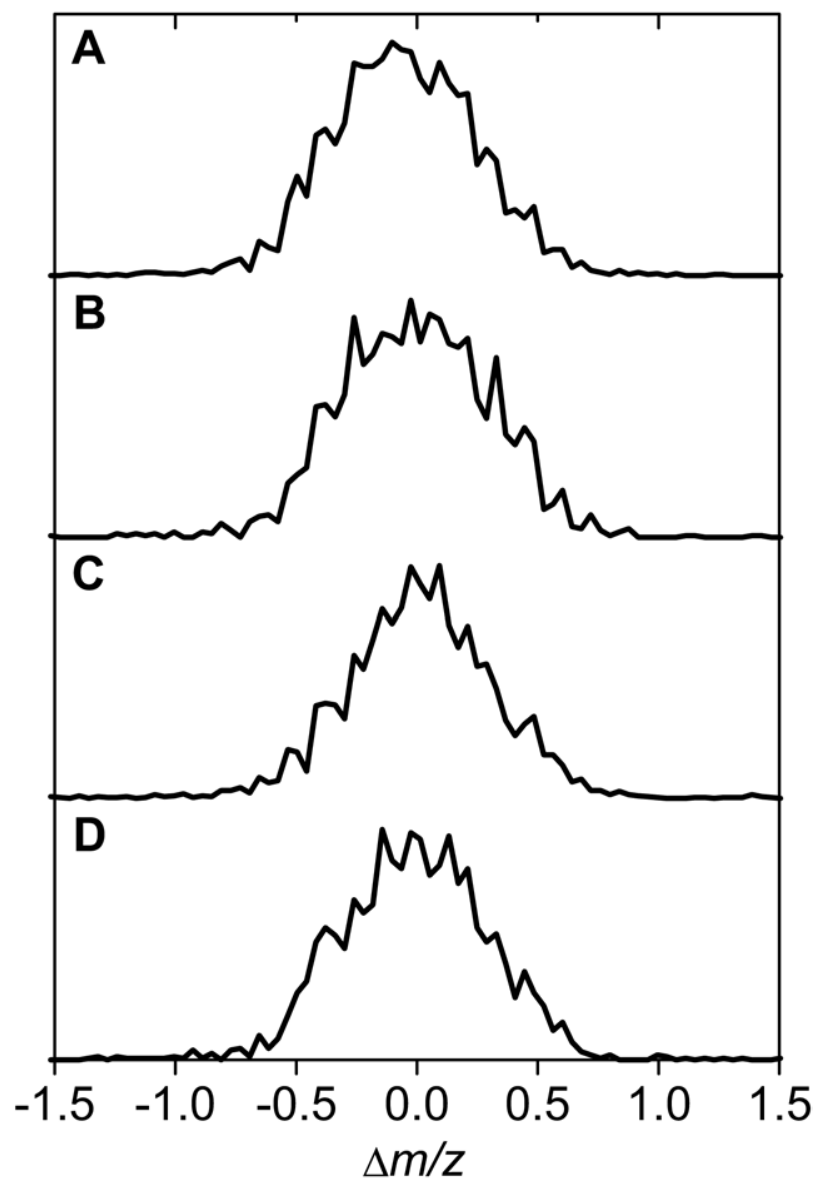

Figure 5. Spectra in the region of the dianion for different degrees of deuterium in the parent ion. The $\mathrm{m} / \mathrm{z}$ of the intact dianion formed after electron capture corresponds to 0 on the axis. The parent ion is (A) $[\mathrm{PP}-\mathrm{H}]^{-},(\mathbf{B})[\mathrm{PP}-\mathrm{H}]^{-} d_{1},(\mathbf{C})[\mathrm{PP}-\mathrm{H}]^{-}-d_{2}$, and (D) $[\mathrm{PP}-\mathrm{H}]^{-}-d_{3}$
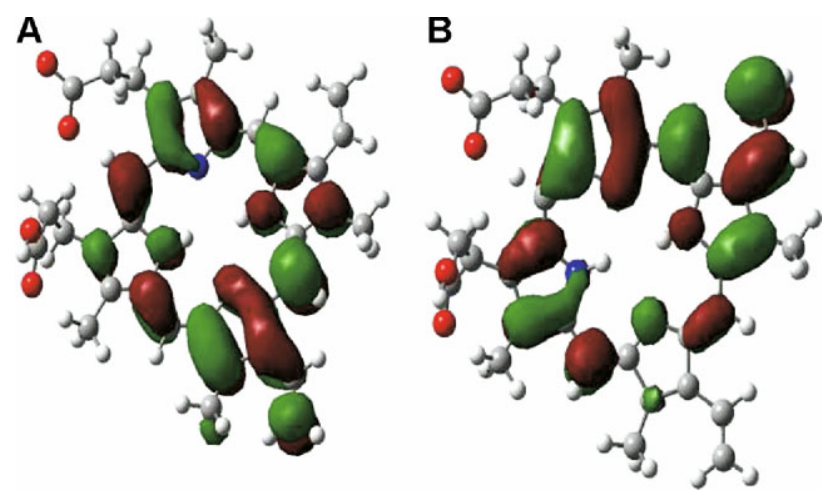

Figure 6. (A) The LUMO of the $[\mathrm{PP}-\mathrm{H}]^{-}$anion. (B) The SOMO of the $[\mathrm{PP}-\mathrm{H}]^{2-}$ dianion.

6-31G $++(\mathrm{d}, \mathrm{p}) / / 6-31 \mathrm{G}+(\mathrm{d}, \mathrm{p})$ level of theory, which is in accordance with work by others [31]. However, the Coulomb repulsion between the two excess charges likely renders the dianion unbound. The vertical electron affinity of the anion was calculated to be $-0.7 \mathrm{eV}$. Since this value is negative, a strong basis set dependence is expected, and the value should be taken with some caution. Also, possibly the adiabatic electron binding energy of the dianion is positive. If the dianion is unstable to electron autodetachment to the continuum, the electron is still trapped because of the repulsive Coulomb barrier, a phenomenon discussed in great detail in earlier studies [32, 33]. One of the excess charges is on the carboxylate group, and the other is delocalized over the porphyrin macrocycle. For comparison, Goto et al. [34] have recently shown that photoexcited porphyrin anions in a storage ring have a long lifetime with respect to electron autodetachment (microseconds to milliseconds), even when the photon energy is larger than the electron binding energy of the anion, that is, super-excited porphyrin anions were formed. It is therefore reasonable to assume the dianions to be rather long-lived even if electronically unbound.

\section{Conclusions}

Electron capture by protoporphyrin IX ions leads to limited fragmentation only. In the case of double electron capture by cations hydrogen loss is observed, whereas in the case of single electron capture by anions, the only dissociation process corresponds to the loss of $\mathrm{CO}_{2} \mathrm{H}$.

\section{Acknowledgments}

This experiment has been performed at ELISA, part of the distributed LEIF infrastructure. The support received by the European Project ITS LEIF (RII3/026015) is gratefully acknowledged. This work was also supported by Danish Natural Science Research Council Grants 21-04-0514 and 272-06-0427 and Carlsbergfondet Grant 2006-01-0229. Finally, we appreciate many good, fruitful, and highly entertaining discussions with Roman Zubarev over the years and look forward to many more! 


\section{References}

1. Zubarev, R. A.; Kelleher, N. L.; McLafferty, F. W. Electron Capture Dissociation of Multiply Charged Protein Cations. A Nonergodic Process. J. Am. Chem. Soc. 1998, 120, 3265-3266.

2. Zubarev, R. A. Reactions of Polypeptide Ions with Electrons in the Gas Phase. Mass Spectrom. Rev. 2003, 22, 57-77.

3. Ge, Y.; Lawhorn, B. G.; El-Naggar, M.; Strauss, E.; Park, J. H.; Begley, T. P.; McLafferty, F. W. Top Down Characterization of Larger Proteins (45 kDa) by Electron Capture Dissociation Mass Spectrometry. J. Am. Chem. Soc. 2002, 124, 672-678.

4. Sze, S. K.; Ge, Y.; Oh, H.; McLafferty, F. W. Top-Down Mass Spectrometry of a 29-kDa Protein for Characterization of Any Posttranslational Modification to Within One Residue. Proc. Natl. Acad. Sci. U.S.A. 2002, 99, 1774-1779.

5. Chamot-Rooke, J.; van der Rest, G.; Dalleu, A.; Bay, S.; Lemoine, J. The Combination of Electron Capture Dissociation and Fixed Charge Derivatization Increases Sequence Coverage for O-Glycosylated and OPhosphorylated Peptides. J. Am. Soc. Mass Spectrom. 2007, 18, 1405-1413.

6. Sweet, S. M. M.; Cooper, H. J. Electron Capture Dissociation in the Analysis of Protein Phosphorylation. Expert Rev. Proteomics 2007, 4, 149-159.

7. Tsybin, Y. O.; Haselmann, K. F.; Emmett, M. R.; Hendrickson, C. L.; Marshall, A. G. Charge Location Directs Electron Capture Dissociation of Peptide Dications. J. Am. Soc. Mass Spectrom. 2006, 17, 1704-1711.

8. Syka, J. E. P.; Coon, J. J.; Schroeder, M. J.; Shabanowitz, J.; Hunt, D. F. Peptide and Protein Sequence Analysis by Electron Transfer Dissociation Mass Spectrometry. Proc. Natl. Acad. Sci. U.S.A. 2004, 101, 95289533.

9. Coon, J. J.; Syka, J. E. P.; Schwartz, J. C.; Shabanowitz, J.; Hunt, D. F. Anion Dependence in the Partitioning between Proton and Electron Transfer in Ion/Ion Reactions. Int. J. Mass Spectrom. 2004, 236, 33-42.

10. Pitteri, S. J.; Chrisman, P. A.; Hogan, J. M.; McLuckey, S. A. Electron Transfer Ion/Ion Reactions in a Three-Dimensional Quadrupole Ion Trap: Reactions of Doubly and Triply Protonated Peptides with $\mathrm{SO}_{2}$. Anal. Chem. 2005, 77, 1831-1839.

11. Gunawardena, H. P.; He, M.; Chrisman, P. A.; Pitteri, S. J.; Hogan, J. M.; Hodges, B. D.; McLuckey, S. A. Electron Transfer versus Proton Transfer in Gas-Phase Ion/Ion Reactions of Polyprotonated Peptides. J. Am. Chem. Soc. 2005, 127, 12627-12639.

12. Srikanth, R.; Wilson, J.; Bridgewater, J. D.; Numbers, J. R.; Lim, J.; Olbris, M. R.; Kettani, A.; Vachet, R. W. Improved Sequencing of Oxidized Cysteine and Methionine Containing Peptides Using Electron Transfer Dissociation. I. Am. Chem. Soc. Mass Spectrom. 2007, 18, 1499-1506.

13. Hvelplund, P.; Liu, B.; Brøndsted Nielsen, S.; Tomita, S. Electron Capture Induced Dissociation of Peptide Dications. Int. J. Mass Spectrom. 2003, 225, 83-87.

14. Chakraborty, T.; Holm, A. I. S.; Hvelplund, P.; Brøndsted Nielsen, S.; Poully, J.-C.; Worm, E. S.; Williams, E. R. On the Survival of Peptide Cations after Electron Capture: Role of Internal Hydrogen Bonding and Microsolvation. J. Am. Soc. Mass Spectrom. 2006, 17, 1675-1680.

15. Holm, A. I. S.; Hvelplund, P.; Kadhane, U.; Larsen, M. K.; Liu, B.; Brøndsted Nielsen, S.; Panja, S.; Pedersen, J. M.; Skrydstrup, T.; Støchkel, K. Williams, E. R.; Worm, E. S. On the Mechanism of ElectronCapture-Induced Dissociation of Peptide Dications from N-15-Labeling and Crown-Ether Complexation. J. Phys. Chem. A 2007, 111, 9641-9643.

16. Schultz, K. N.; Hakansson, K. Rapid Electron Capture Dissociation of Mass-Selectively Accumulated Oligodeoxynucleotide Dications. Int. I. Mass Spectrom. 2004, 234, 123-130.

17. Adamson, J. T.; Hakansson, K. Electron Capture Dissociation of Oligosaccharides Ionized with Alkali, Alkaline Earth, and Transition metals. Anal. Chem. 2007, 79, 2901-2910.

18. Liang, X.; Liu, J.; LeBlanc, Y.; Covey, T.; Ptak, A. C.; Brenna, J. T.; McLuckey, S. A. Electron Transfer Dissociation of Doubly Sodiated Glycerophosphocholine Lipids. J. Am. Soc. Mass Spectrom. 2007, 18, 1783-1788.
19. Nielsen, A. B.; Hvelplund, P.; Liu, B.; Brøndsted Nielsen, S.; Tomita, S. Coulomb Explosion upon Electron Attachment to a Four-Coordinate Monoanionic Metal Complex. J. Am. Chem. Soc. 2003, 125, 9592-9593.

20. Drenck, K.; Hvelplund, P.; McKenzie, C. J.; Brøndsted Nielsen, S. Identification of the Short-lived $\mathrm{Au}\left(\mathrm{N}_{3}\right)_{4}{ }^{2-}$ Dianion from its Coulomb Explosion Products. Int. J. Mass Spectrom. 2005, 244, 144-147.

21. Hvelplund, P.; Liu, B.; Brøndsted Nielsen, S.; Panja, S.; Poully, J.-C.; Støchkel, K. Electron Capture Induced Dissociation of Peptide Ions: Identification of Neutral Fragments from Secondary Collisions with Cesium Vapour. Int. J. Mass Spectrom. 2007, 263, 66-70.

22. Hayakawa, S.; Hashimoto, M.; Matsubara, H.; Turecek, F. Dissecting the Proline Effect: Dissociations of Proline Radicals Formed by Electron Transfer to Protonated Pro-Gly and Gly-Pro Dipeptides in the Gas Phase. J. Am. Chem. Soc. 2007, 129, 7936-7949.

23. Boltalina, O. V.; Hvelplund, P.; Jørgensen, T. J. D.; Larsen, M. C Larsson, M. O.; Sharoitchenko, D. A. Electron Capture by Fluorinated Fullerene Anions in Collisions with Xe Atoms. Phys. Rev. A 2000, 62, 023202.

24. Larsson, M. O.; Hvelplund, P.; Larsen, M. C.; Shen, H.; Cederquist, H. Schmidt, H. T. Electron Capture and Energy Loss in $\sim 100 \mathrm{keV}$ Collisions of Atomic and Molecular Ions on $\mathrm{C}_{60}$. Int. J. Mass Spectrom. 1998, $177,51-62$.

25. GAUSSIAN 98, Revision A9, Trucks, G. W., Schlegel, H. B., Scuseria, G. E., Robb, M. A., Cheeseman, J. R., Zakrzewski, V. G., Montgomery, J. A. Stratmann, R. E., Burant, J. C., Dapprich, S., Millam, J. M., Daniels, A. D., Kudin, K. N., Strain, M. C., Farkas, O., Tomasi, J., Barone, V., Cossi, M., Cammi, R., Mennucci, B., Pomelli, C., Adamo, C., Clifford, S., Ochterski, J., Petersson, G. A., Ayala, P. Y., Cui, Q., Morokuma, K., Malick, D. K, Rabuck, A. D., Raghavachari, K., Foresman, J. B., Cioslowski, J., Ortiz, J. V., Stefanov, B. B., Liu, G., Liashenko, A., Piskorz, P., Komaromi, I., Gomperts, R., Martin, R. L., Fox, D. J., Keith, T., Al-Laham, M. A., Peng, C. Y., Nanayakkara, A., Gonzalez, C., Challacombe, M., Gill, P. M. W., Johnson, B. G., Chen, W., Wong, M.W., Andres, J. L., Head-Gordon, M., Replogle, E. S., Pople, J. A. Gaussian, Inc., Pittsburgh, PA; 1998.

26. Nonose, S.; Tanaka, H.; Okai, N.; Shibakusa, T.; Fuke, K. Photo-Induced Reactions of Hemin ${ }^{+}(\mathrm{DMSO})$ Clusters $(\mathrm{n}=0-3)$ Produced with Electrospray Ionization. Eur. Phys. J. D Atomic Mol. Opt. Plasma Physics 2002 20, 619-626.

27. Charkin, O. P.; Klimenko, N. M.; Nguyen, P. T.; Charkin, D. O.; Mebel, A. M.; Lin, S. H.; Wang, Y.-S.; Wei, S.-C.; Chang, H.-C. Fragmentation of Heme and Hemin $(+)$ with Sequential Loss of Carboxymethyl Groups: A DFT and Mass-Spectrometry Study. Chem. Phys. Lett. 2005, 415, 362-369.

28. Charkin, O. P.; Klimenko, N. M.; Charkin, D. O.; Chang, H.-C.; Lin, S.-H Theoretical DFT Study of Fragmentation and Association of Heme and Hemin. J. Phys. Chem. A 2007, 111, 9207-9217.

29. Hvelplund, P.; Brøndsted Nielsen, S.; Andersen, J. U.; Sørensen, M.; Jørgensen, T. J. D. Electron Loss from Multiply Protonated Lysozyme Ions in High Energy Collisions with Molecular Oxygen. J. Am. Soc. Mass Spectrom. 2001, 12, 889-893.

30. Liu, B.; Hvelplund, P.; Brøndsted Nielsen, S.; Tomita, S. Hydrogen Loss from Nucleobase Nitrogens upon Electron Attachment to Isolated DNA and RNA Nucleotide Anions. J. Chem. Phys. 2004, 121, 4175-4179.

31. Tao, M.; Zhou, X.; Jing, M.; Liu, D.; Xing, J. Fluorescence and Electrochemical Properties of Naphthylporphyrins and Porphyrin-Anthraquinone Dyads. Dyes Pigments 2007, 75, 408-412.

32. Wang, X.-B.; Wang, L.-S. Observation of Negative Electron-Binding Energy in a Molecule. Nature 1999, 400, 245-248.

33. Wang, X.-B.; Ding, C. F.; Wang, L.-S. Electron Tunneling through the Repulsive Coulomb Barrier in Photodetachment of Multiply Charged Anions. Chem. Phys. Lett. 1999, 307, 391-396.

34. Goto, M.; Yasuda, Y.; Jinno, S.; Takao, T.; Hanada, K.; Tanuma, H.; Azuma, T.; Sugiura, K.-I.; Shiromaru, H.; Achiba, Y. Electron Detachment of Super-Excited Porphyrin Anions in an Electrostatic Ion Storage Ring. Eur. Phys. J. D Atomic Mol. Opt. Plasma Physics 2007, 43, 65-68. 